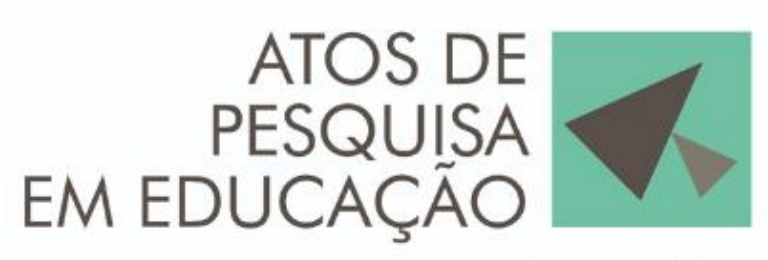

ISSN: 1809-0354

\title{
EDUCAÇÃO ESTÉTICA: UM OLHAR SOBRE SÃO LUÍS, MARANHÃO
}

\author{
AESTHETIC EDUCATION: A LOOK AT SÃO LUÍS, MARANHÃO
}

EDUCACIÓN ESTÉTICA: UMA MIRADA A SÃO LUÍS, MARANHÃO

\author{
PERINI, Janine Alessandra \\ Janine.perini@ufma.br \\ UFMA - Universidade Federal do Maranhão \\ ORCID: https://orcid.org/0000-0002-0448-6824
}

\begin{abstract}
RESUMO: O artigo reflete sobre a cidade de São Luís a partir do centro histórico e de dois artistas: Paulo Cezar e Márcio Vasconcelos. Conhecer São Luís pelos olhos desses artistas é tentar fazer o exercício de olhar a obra para decifrar a cidade, utilizando-se da leitura crítica, olhando a cidade por outra perspectiva, pela experiência do outro. Utilizou-se o método materialista histórico-dialético, buscando compreender a cidade em termos visuais, fazendo relações da imagem com características políticas, econômicas, históricas, sociais e culturais. Concluímos que a cidade é reconhecida internacionalmente pelas belas fachadas dos sobrados, revestidos de azulejos portugueses e pela diversidade cultural existente pela miscigenação do índio, do negro e do europeu.
\end{abstract}

Palavras-chave: Estética. São Luís. Artes Visuais.

ABSTRACT The article reflects on the city of São Luís from the historic center and two artists: Paulo Cezar and Márcio Vasconcelos. Knowing São Luís through the eyes of these artists is trying to make the exercise of looking at the work to decipher the city, using a critical reading, looking at the city from another perspective, through the experience of the other. The historical-dialectical materialist method was used, seeking to understand the city in visual terms, making relations between the image and political, economic, historical, social and cultural characteristics. We conclude that the city is internationally recognized for its beautiful facades of the houses, covered with Portuguese tiles and for the cultural diversity that exists due to the miscegenation of the Indian, the black and the European.

Keywords: Aesthetic. São Luís. Visual Arts.

RESUMEN El artículo reflexiona sobre la ciudad de São Luís del centro histórico y dos artistas: Paulo Cezar y Márcio Vasconcelos. Conocer São Luís a través de la mirada de estos artistas es intentar hacer el ejercicio de mirar la obra para descifrar la ciudad, utilizando una lectura crítica, mirando la ciudad desde otra perspectiva, a través de la experiencia del otro. Se utilizó el método materialista histórico-dialéctico, buscando entender la ciudad en términos visuales, estableciendo relaciones entre la imagen y las características políticas, económicas, históricas, sociales y culturales. Concluimos 


\section{ATOS DE \\ PESQUISA \\ EM EDUCAÇÃO}

ISSN: 1809-0354

2

que la ciudad es reconocida internacionalmente por las hermosas fachadas de las casas, cubiertas con tejas portuguesas y por la diversidad cultural que existe debido al mestizaje de los indígenas, el negro y el europeo.

Palabras clave: Estética. São Luís. Artes Visuales.

\section{INTRODUÇÃO}

Nosso estudo debruçar-se-á sobre a cidade de São Luís, focalizando a arte e a cultura, considerando arte e cidade como uma só coisa. Nesse contexto, utilizamos Argan (2005), que analisa o espaço urbano como um espaço de objetos. Assim, São Luís foi observada/contemplada/analisada nessa perspectiva, como obra de arte, sendo um produto da civilização histórica e que continua com interferências contínuas. Por isso, refletimos sobre história, memória e patrimônio da humanidade, pensando a cidade em suas dimensões estéticas e culturais.

Pensar a cidade como obra de arte é pensar a arquitetura como uma série de espaços articulados. Para Pinheiro (2008), cada espaço possui qualidades particulares, que se relacionam entre si. "O desafio do desenho da cidade está em construir harmoniosamente as experiências no espaço ao longo do tempo" (PINHEIRO, 2008, p. 328). Para a autora, o objetivo de um projeto arquitetônico é mexer com as emoções e sentimentos das pessoas enquanto elas se movem pelo espaço.

Com base nesse pensamento, o objetivo é pensar/refletir a cidade como imagem, e suas práticas sociais como geradoras de cultura urbana. Primeiramente, focaremos nosso olhar no centro histórico da cidade, por seus encantos e desencantos estéticos, sociais e históricos. Em seguida, traremos dois artistas para nos mostrar um olhar sobre a cidade de São Luís e do estado do Maranhão.

\section{CENTRO HISTÓRICO DE SÃO LUÍS}

Uma particularidade importante da totalidade de São Luís é o seu centro histórico, por ser um espaço de convivência, onde pessoas de todas as idades, gêneros, raças e classe social participam dele por meio de relações antagônicas. Pereira (2006) informa que do século XVII ao início do XIX, esse espaço era uma área 


\section{ATOS DE \\ PESQUISA \\ EM EDUCAÇÃO}

ISSN: 1809-0354

3

de grande fluxo comercial, com pessoas ricas e pobres; escravizados e livres; brancos e pretos. Um território marcado por relações afetivas e comerciais, permeadas por tensões e instabilidades sociais.

Hoje em dia, as relações são outras, mas não deixam de ser conflituosas. Alguns grupos sociais visitam o espaço para participar de atividades culturais, artísticas e sociais, utilizando-o como área de lazer; outros, trabalham em instituições que utilizam as obras arquitetônicas do centro histórico que foram preservadas e revitalizadas; alguns sem muita opção moram nos casarões abandonados; outros, ainda, frequentam o espaço para vender sua arte e/ou sua força de trabalho aos turistas.

O centro histórico de São Luís, com seu valor arquitetônico, paisagístico, histórico e cultural, tornou-se Patrimônio Mundial, em 1997, com cerca de quatro mil imóveis dos séculos XVIII e XIX. Esse processo aconteceu lentamente. Figueiredo (2012) conta que, em 1940, aconteceu o primeiro tombamento arquitetônico em São Luís: o Portão e a Capela de São José da Quinta das Laranjeiras. A partir dessa época começaram a discutir e a intervir no sentido de preservar alguns imóveis isolados do centro histórico, o que foi se intensificando a partir do final de 1970.

O passado está presente no cotidiano dos ludovicenses e dos que visitam a cidade. Um passado marcado pelo seu valor histórico: sobrados com rico valor arquitetônico, caracterizados por um período próspero para a nobreza, principalmente pela produção do algodão e de muito trabalho forçado pelos escravizados, mão-deobra africana e afro-brasileira.

O tombamento desse conjunto arquitetônico agregou um valor econômico ao valor artístico e cultural, pois quando a classe alta abandonou a área central e foi morar em áreas consideradas nobres, o centro perdeu seu valor imobiliário e entrou num período de declínio e abandono, restando apenas seu valor histórico, artístico e cultural.

Em relação ao valor artístico, Argan afirma: "Qualquer que seja a sua antiguidade, a obra de arte sempre ocorre como algo que acontece no presente" (ARGAN, 2005, p. 25). O autor continua seu pensamento nos lembrando de que "[...] a obra de arte não tem para nós o mesmo valor que tinha para o artista que a fez $\mathrm{e}$ para os homens da sua época. A obra é sempre a mesma, mas as consciências 


\title{
ATOS DE

mudam" (ARGAN, 2005, p. 25). O valor dos casarões do centro histórico, hoje, não é maior ou menor do que no século XVIII, mas diferente. As relações são outras. Antes a relação era de moradia e comércio, agora, as edificações entram no mercado capitalista com foco no turismo e no lazer. As reformas e recuperações dos imóveis transformam os espaços abandonados pela classe alta, em espaços, que incentivam atividades de cunho histórico, artístico e cultural.

O centro histórico tornou-se um dos pontos turísticos mais importantes do estado e do país, com o intuito de valorizar a história da cidade, ressaltando a memória e a cultura do povo negro e europeu. A beleza do centro histórico de São Luís são os casarios tombados, a arquitetura colonial luso-brasileira, revestida com os azulejos portugueses. Esse conjunto de casarões dá valor e forma estética ao centro histórico. Assis (2012) escreve sobre essa herança lusitana:

\begin{abstract}
Portugal fez de São Luís a mais lusitana das capitais brasileiras, combinando senso artístico e proveito utilitário de sua aplicação. Dessa forma, a cidade preserva o maior aglomerado urbano de azulejos dos séculos XVIII e XIX, em toda a América Latina. Eles assumem importância no contexto universal da criação artística, pela longevidade de seu uso, sem interrupção durante cinco séculos, resistindo a tempos chuvosos e amenizando o calor do verão, devido aos tons brancos que refletem os raios solares, tornando mais amena a temperatura no interior das edificações. [...] Assim, essa cultura material ludovicense, respeitada mundialmente, resgata a identidade e memória de seu povo, retrata beleza e desperta orgulho nas pessoas que valorizam a história. Essas construções coloniais devem ser apreciadas não apenas como um produto da burguesia da época, mas principalmente como oriundas da mão-de-obra africana, pois foram os negros que ergueram, com sua força e bravura, apesar das dores e angústias vivenciadas por eles no passado, o centro histórico de São Luís. Assim, a herança não é apenas portuguesa, mas também africana (ASSIS, 2012, p. 01).
\end{abstract}

A autora nos lembra que São Luís foi constituída por uma miscigenação forçada entre povos africanos, indígenas e europeus. No centro histórico de São Luís contempla-se a arte portuguesa da azulejaria, a maioria com desenhos geométricos com predomínio das cores branca e azul (Ver Figura 1). 


\section{ATOS DE \\ PESQUISA \\ EM EDUCAÇÃO}

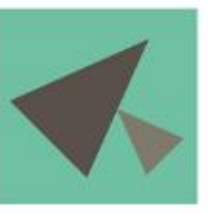

ISSN: 1809-0354

Figura 1- Janine Perini. Azulejos portugueses, Fotografia, 2019.

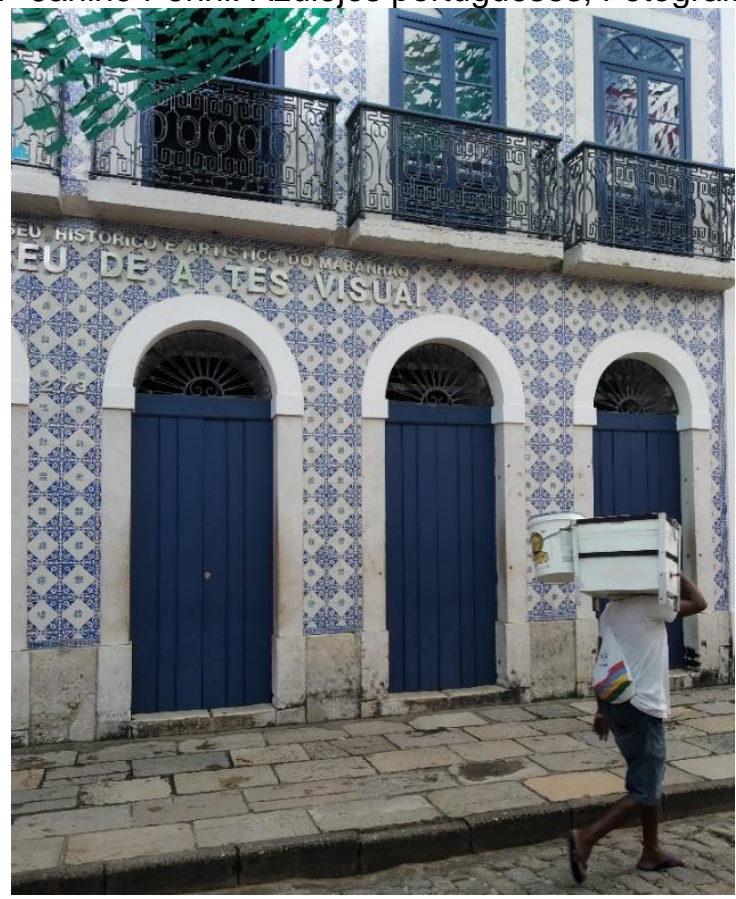

Fonte: Acervo da pesquisadora.

Dentro das categorias estéticas, a arquitetura colonial luso-brasileira entra na mais geral do estético, o belo. As categorias só existem em determinadas condições históricas, sociais e culturais, como afirma Vázquez:

As categorias estéticas são históricas. Não podem ser separadas da história da realidade da qual são sua expressão teórica, abstrata, nem tampouco de sua própria história: história dos ideais estéticos e das realizações artísticas desses ideais, e tudo isso como parte indissolúvel da história real da sociedade (VÁZQUEZ, 1999, p. 189).

O autor continua seu pensamento e coloca que "[...] o belo corresponde à arte clássica na qual a figura humana encontra o equilíbrio de conteúdo e forma" (VÁZQUEZ, 1999, p. 189). O centro histórico pode ser considerado belo por ser correspondente ao belo clássico, que valoriza a harmonia, a proporção, a simetria e o equilíbrio, aproximando-se do belo clássico pelo efeito que este conjunto de casarios revestidos com azulejo produz nos observadores. Tudo isso, encanta os olhares de turistas e moradores, suscitando prazer ao caminhar pelas ruas estreitas e sentindo de perto o cheiro da história e da memória guardados nessas construções. Vázquez (1999) aborda que a definição do belo como prazer é encontrada nas teorias de Platão, Tomás de Aquino, Hume e Kant: 


\section{ATOS DE

Já na Grécia clássica o mesmo Platão, que constrói o paradigma metafísico, idealista, do belo, o caracteriza como "[...] o que nos causa prazer, nem toda a espécie de prazeres, mas os que provêm da visão e da audição". E entre os objetivos que o produzem enumera os que "encantam nosso olhar: homens belos, desenhos em cores, pinturas, esculturas, belos sons, música em geral..." Essa definição, que Platão considera "uma boa definição do belo", correrá com boa sorte ao longo da história do pensamento estético. Tomás de Aquino dirá também, na Idade Média, que belo é "o que agrada à vista". E David Hume, no século XVIII, põe em relação direta prazer e beleza e define essa última como "poder especial de produzir prazer". Kant caracterizava essa relação mais claramente ao delimitar o tipo de prazer e de objeto que estão em jogo. Trata-se, assim mesmo, de um prazer desinteressado e não apenas individual, já que se caracteriza por ser um prazer universal, compartilhado por outros; embora com a particularidade de que essa universalidade, sendo subjetiva, não se acha submetida a regras. Quanto ao objeto, trata-se de que, por sua forma, por possuir uma configuração adequada, suscita prazer ao ser percebido (VÁZQUEZ, 1999, p. 189).

Por meio da citação de Vásquez, percebemos que o centro histórico de São Luís é belo por ser harmônico, proporcionado, equilibrado e por produzir prazer ao ser apreciado e por ser concebido em sua dupla vertente: objetiva e subjetiva. $\mathrm{O}$ autor ainda coloca que embora as outras categorias estéticas, como o feio e o trágico, também produzam algum prazer, nunca é da mesma maneira e com a mesma intensidade do que a categoria do belo.

Além de belos, os azulejos são úteis, porque protegem as construções da chuva e do sol, pois o clima da cidade é muito quente e úmido e as casas são de taipa. Os azulejos têm a função de impermeabilizar. Pode-se pensar nessa utilidade do belo pelo legado das ideias socráticas, como mostra Vázquez:

Mas Sócrates não só afirma que o escudo é belo e útil, como também garante que é belo na medida de sua utilidade. Quer dizer, é belo porque se adapta a, ou cumpre, sua função (tese fundamental da estética funcionalista contemporânea). $O$ belo, pois, se confunde com o útil, entendido em um sentido prático-material ou funcional (VÁZQUEZ, 1999, p. 163).

O autor afirma que Sócrates vincula o belo com o útil. Já para Kant, o belo e o útil são incompatíveis. Mas Vásquez não reduz a arte às posições antagônicas de Sócrates e Kant e sim para ele "[...] a arte não só não é inútil, mas sim útil para elevar e enriquecer o ser humano" (VÁZQUEZ, 1999, p. 165). E essa elevação e esse enriquecimento são sentidos ao se passear pelo centro histórico de São Luís. Há essa relação estética entre nós (sujeito) e os casarios tombados (objeto estético), como se percebe na Figura 2. 


\section{ATOS DE \\ PESQUISA \\ EM EDUCAÇÃO}

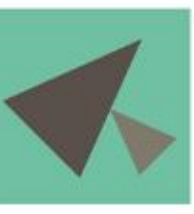

ISSN: 1809-0354

7

Fonte: http://omarjunior.com/fotografia/projeto/banco-de-imagem-sao-luis-maranhao/

Infelizmente, encontramos a oposição em alguns lugares do centro. Essa sensação de enlevação encontrada nos espaços revitalizados não é sentida e, sim, tristeza e medo, como se nota na Figura 3. Casarões abandonados se desfazendo, dão a sensação de medo ao passar por perto e ser atingido com a queda de algum fragmento da construção. As arquiteturas antigas, que ainda resistem ao poder destruidor do tempo, deveriam ser preservadas e conservadas pelo poder público em parceria com a sociedade civil, pois fazem parte do patrimônio cultural maranhense.

Figura 3-Janine Perini. Casarões abandonados, Fotografia, 2019.

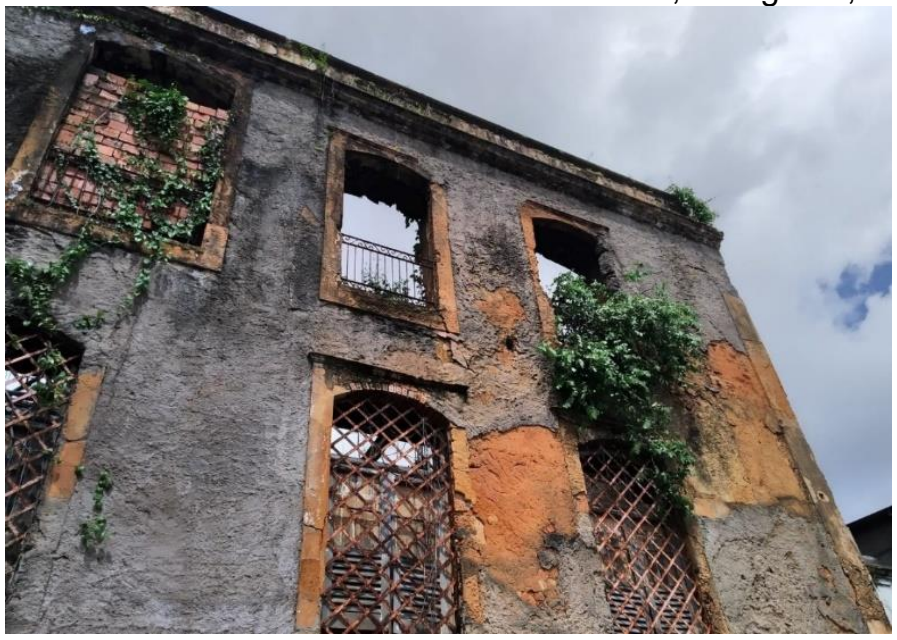

Fonte: Acervo da pesquisadora.

A sensação de medo também pode ser sentida em outros becos e ruas em razão da má iluminação e de atos de vandalismo, ocorridos pelo abandono e pela falta de segurança. Argan, como historiador da arte e com experiência como prefeito de Roma, aborda, assim, o abandono nos centros históricos: 


\section{ATOS DE

A paralisia econômica e social dos centros históricos é quase inevitável: as pequenas atividades artesanais e comerciais são inevitavelmente sufocadas pela produção industrial e respectivos grandes centros de distribuição; os custos de restauração e manutenção dos velhos edifícios comportam despesas que, claro, não podem ser enfrentadas pela população indígena; o engarrafamento do trânsito e o acúmulo de automóveis estacionados estão em contradição com as antigas estruturas; o processo de abandono, sobretudo por parte das gerações jovens, é rápido. Com tudo isso, os solos urbanos conservam preços elevadíssimos que favorecem as manobras proibidas, mas difíceis de enfrentar, da especulação imobiliária. A substituição das velhas classes populares e pequeno-burguesas por novas classes ricas provoca verdadeiras falsificações, não só porque os edifícios são geralmente esvaziados, reduzidos à simples fachada, reestruturados em seu interior, mas também porque as próprias classes originais constituem um bem cultural que deveria ser protegido (ARGAN, 2005, p. 77).

Para o autor, salvar o centro histórico, ou seja, recuperar sua função habitacional, com a permanência das classes originárias, é pensar numa política urbanística que considere globalmente todos os problemas, sendo necessário mexer na cidade como um todo. Assim, para preservar o centro histórico de São Luís, a cidade precisa ser reestruturada por inteiro, uma questão nada fácil de resolver conhecendo-se o cotidiano da cidade. Hoje, os moradores do centro histórico têm uma realidade socioeconômica diferente dos moradores da classe dominante dos períodos áureos do centro. Muitos imóveis foram invadidos e os moradores não têm como arcar com os custos de manutenção desses imóveis, vivendo, muitas vezes, em situações de risco e insalubres. Outro ponto é a falta de policiamento na região, que faz com que se torne um espaço perigoso, com ações de vandalismo e de criminalidade.

Muitos são os desafios para se conseguir diminuir a sujeira, a violência, o vandalismo, o consumo abusivo de drogas, a invasão e o abandono do centro histórico. Para começar precisa-se acabar com as desigualdades sociais, a segregação das classes sociais existentes na cidade de São Luís, ampliando o compromisso político com o povo por meio de ações pontuais para a classe trabalhadora e de políticas públicas voltadas para o segmento mais carente da sociedade ludovicense.

São Luís é um espaço construído historicamente. É um lugar complexo se pensarmos nas questões políticas, econômicas e sociais. A cidade está na contramão entre a cidade antiga e a moderna. $O$ seu centro histórico pode ser visto como um labirinto, com suas ruas estreitas e tortuosas, casas com muros invadindo a rua. Para conhecer, temos que explorar, andar para frente e para trás, de um lado e para 0 


\section{ATOS DE

outro. Tem que se adentrar pelas ruelas, pois não temos uma visão do todo, e sim, dos detalhes que vão compondo o espaço.

Benjamin (2006) faz uma analogia entre cidades e paisagens. Para o autor, o labirinto pode ser visto como símbolo da cidade antiga. Então, o centro histórico pode ser pensado também como cidade-labirinto: deixar perder-se pela cidade para encontrar a si próprio. $\mathrm{O}$ autor procura aproximar a memória do indivíduo à memória da cidade. Para ele, é necessário ter tempo para a contemplação, para ver a cidade com olhar da infância, com olhar afetuoso.

Caminhando e se perdendo pelo labirinto do centro histórico de São Luís, temos várias sensações: uma de medo e outra de deslumbre, uma durante o dia e outra à noite. Com a luz solar, encontramos cores: as dos casarões, das mercadorias vendidas nas lojas, das pessoas, dos azulejos, do céu, dos alimentos, dos artesanatos e das artes vendidas nos mercados e restaurantes, do processo de miscigenação de culturas. Mercados e algumas lojas servem também de passagens de uma rua para outra ou de uma esquina para outra. Cada entrada pode ser vista como uma possível saída e cada saída como uma possível entrada, como lembra Benjamin (2006), quando apresenta as Passagens Parisienses ${ }^{1}$. As do centro histórico de São Luís diferenciam-se das luxuosas francesas, pois aqui encontramos o caos e a desordem, pelo excesso de objetos e cores, chamando a atenção para o todo, sem conseguir prestar atenção nos detalhes, mas que se identificam com as parisienses, pois atravessam quarteirões inteiros e são centros de mercadorias.

À noite, bares e restaurantes com música ao vivo, apresentações de reggae e de Tambor de Crioula ${ }^{2}$ pelas ruas e escadarias, como mostra a Figura 4, evocam outras sensações.

\footnotetext{
1 O livro Passagens de Walter Benjamin é escrito entre 1927 e 1940, um conjunto de textos sobre a cidade de Paris no século XIX. As passagens são as galerias comerciais e as lojas de departamentos na capital francesa, onde as entradas e saídas são as mesmas ao mesmo tempo. Essas passagens expressam o progresso capitalista e o fetichismo das mercadorias.

2 O Tambor de Crioula do Maranhão é uma forma de expressão de matriz afro-brasileira que envolve dança circular, canto e percussão de tambores. Seja ao ar livre, nas praças, no interior de terreiros, ou associado a outros eventos e manifestações, é realizado sem local específico ou calendário pré-fixado e praticado especialmente em louvor a São Benedito, na maioria dos municípios do Maranhão. Disponível em: http://portal.iphan.gov.br/pagina/detalhes/63/. Acesso em: 06 jul. de 2021.
} 


\section{ATOS DE \\ PESQUISA \\ EM EDUCAÇÃO}

ISSN: 1809-0354

10

Figura 4-Tambor de Crioula/ Manifestação cultural quilombola.

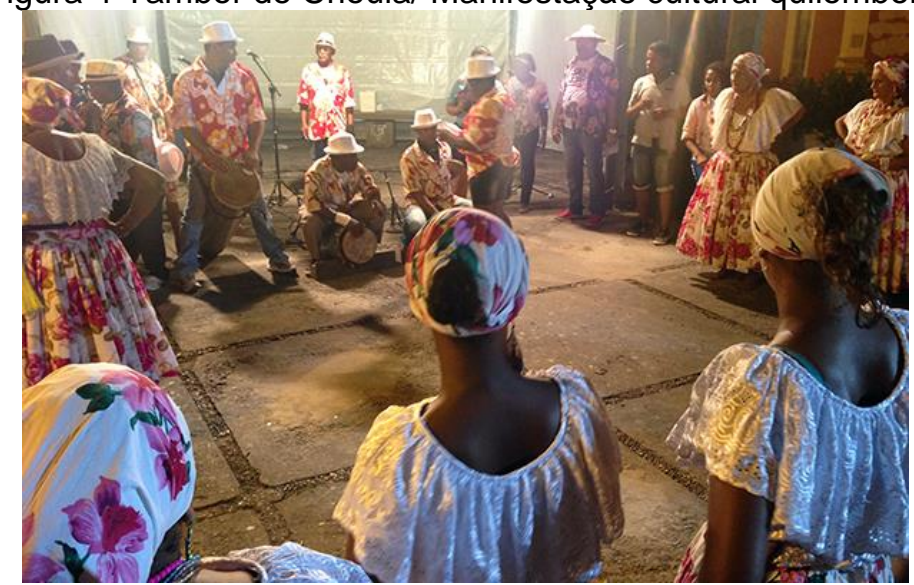

Fonte: http://www.penaestrada.blog.br/o-centro-historico-de-sao-luis/

Muita alegria e descontração, cheiro de arte e cultura no ar, mas ao sair do centrinho preservado, iluminado, orgânico e se perder no labirinto do centro histórico, uma sensação de medo e insegurança começa a aflorar. O centro histórico está abandonado em alguns lugares, por isso há um caráter contraditório, entre os espaços com vida, preservado, revitalizado e os sujos, escuros e perigosos.

\section{EXPERIÊNCIAS VISUAIS: O OLHAR DOS ARTISTAS}

São Luís foi representada por muitos artistas, por meio da literatura, música, artes visuais, entre outras linguagens artísticas. Para refletir sobre a cidade, escolhemos dois artistas visuais: Paulo Cezar Alves de Carvalho e Márcio Vasconcelos. Conhecer São Luís pelos olhos desses artistas é tentar fazer o exercício de olhar a obra para decifrar a cidade, utilizando-se da leitura crítica, olhando a cidade por outra perspectiva, pela experiência do outro. O uso dessas metáforas busca compreender a cidade em termos visuais. Sabendo que a imagem possibilita milhares de leituras, este estudo pretende fazer relações da imagem com a cidade estudada, levando em consideração características políticas, econômicas, históricas, sociais e culturais.

Paulo Cezar Alves de Carvalho, artista plástico, nascido em 1960, na cidade de Brejo, Maranhão, desde pequeno mora na capital do estado, São Luís. Em 1985, graduou-se no curso de Licenciatura em Educação Artística pela Universidade Federal do Maranhão (UFMA) e fez uma especialização em História do Maranhão pela mesma 


\section{ATOS DE

instituição em 2006. Em 1998/99, fez estágio com Bolsa do MINC/Brasil no Museu Nacional do Azulejo em Lisboa, Portugal. Atualmente, é professor auxiliar do Departamento de Artes da UFMA. Suas obras possuem um cunho político-social, retratando o cotidiano da cidade de São Luís, (Figura 5).

Figura 5- Paulo César Alves de Carvalho. Sandálias do Índio Galdino, 2012. Pintura sobre azulejo.

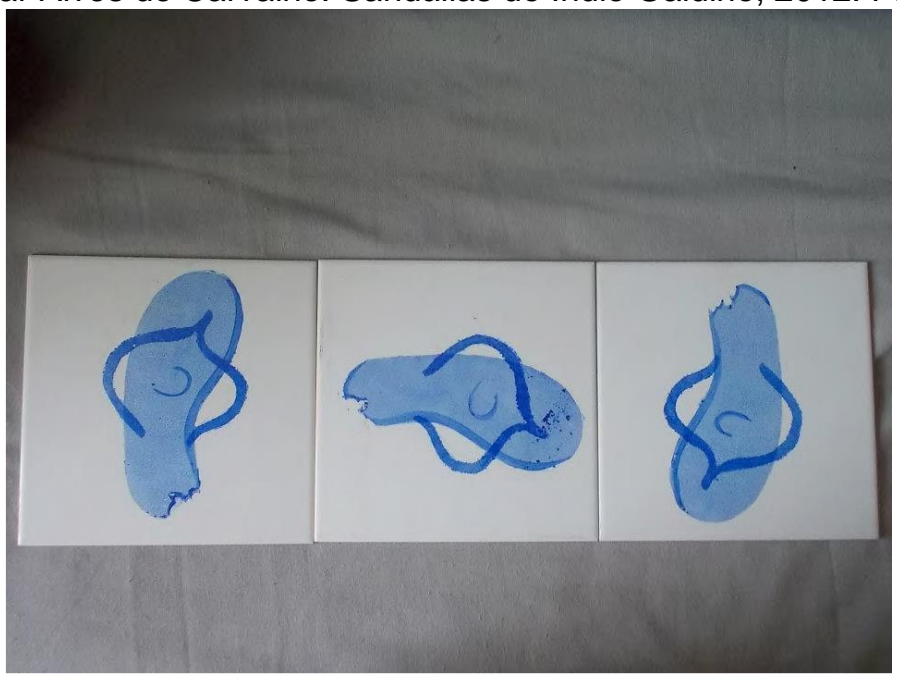

Fonte: PERINI, 2017, p. 234.

A obra Sandálias do Índio Galdino foi criada como forma de expressão do artista acerca dos crimes realizados contra os indígenas. Entre tantas violências e assassinatos contra esse povo, podemos citar a morte do índio pataxó Galdino Jesus dos Santos ${ }^{3}$, em Brasília, quando cinco jovens atearam fogo nele, enquanto dormia no ponto de ônibus. $\mathrm{O}$ artista em uma entrevista destacou que:

Poética e Denúncia, a sandália tipo chinelo de dedo feito em borracha, sabe? A popular japonesa, ou a nobre marca sandália Havaiana, ou uma subversão... a pobre marca Dupé, marca mais barata, e que figurava num conteúdo formal de painel azulejar ou simplesmente um padrão avulso azulejar. Estampada em azul cobalto, prodígio do barroco joanino português, e lá estava a chinela toda corroída, carcomida à altura do calcanhar, um desgaste épico-social, onde o topo do pé pelo calcanhar não será mais o potencial de Aquiles, mas um pé vadio e sujo, sujo de lama com couro rachado e bichorento (existe essa palavra? Acabo de criar). Assim é o Brasil genocida. Objetos daqueles que são diariamente assassinados na rua. Objetos que sempre adornam a cena do crime (PERINI, 2017, p. 232).

\footnotetext{
3 "Há 22 anos, um crime chocava o país e o mundo. Na madrugada de 20 de abril de 1997, cinco jovens de classe média atearam fogo no cacique do povo Pataxó Galdino Jesus dos Santos, que dormia em um ponto de ônibus em Brasília. O indígena, então com 44 anos, teve $95 \%$ do corpo queimado e morreu dois dias após o atentado". Disponível em: http://www.midia1508.org/2019/04/20/ha-22-anos-liderindigena-galdino-pataxo-era-queimado-vivo-em-brasilial. Acesso em: 01 jul. 2021.
} 


\section{ATOS DE \\ PESQUISA \\ EM EDUCAÇÃO}

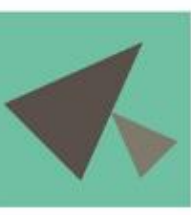

ISSN: 1809-0354

12

O artista, a partir do azulejo, material encontrado em seu dia a dia, expressa sua indignação com o genocídio, situação muito encontrada no Brasil e, consequentemente, no Maranhão. Os povos Guajajara e Awá são constantemente ameaçados por madeireiros que exploram ilegalmente a Terra Indígena Arariboia ${ }^{4}$, no Maranhão. Outra obra relacionada com a temática indígena pode ser vista na Figura 6.

Figura 6- Paulo César Alves de Carvalho. Pataxó, 2001. Pintura sobre azulejo.

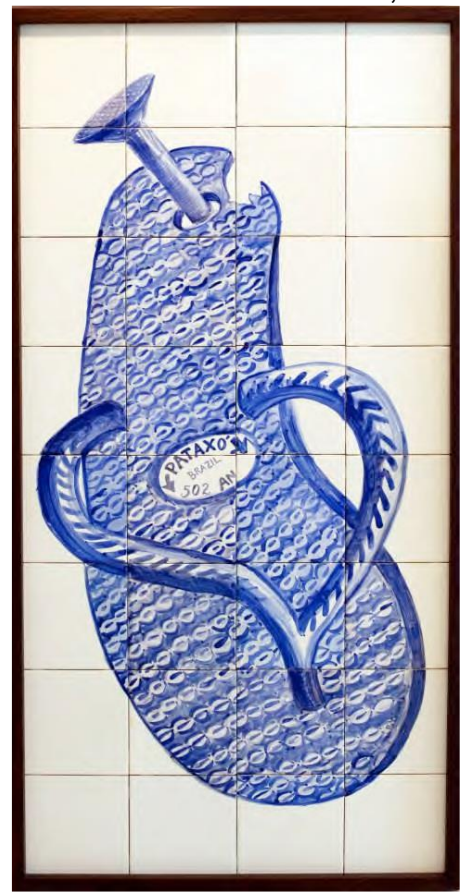

Fonte: PERINI, 2017, p. 233.

Nessas duas obras, Paulo César exibe a imagem do chinelo de borracha com marcas do tempo. Um chinelo desgastado, carcomido, utilizado pela maioria da classe trabalhadora, da classe explorada. Na Figura 6, ele coloca uma marca na sandália: "Pataxó". Nos lembrando de que os índios viraram uma mercadoria na sociedade capitalista.

\footnotetext{
4 "Em dezembro do ano passado, dois caciques Guajajara foram mortos ao voltarem de uma reunião com a Fundação Nacional do Índio (Funai) e a Eletronorte. Eles foram atingidos por vários disparos de arma de fogo na BR 226, no município de Jenipapo dos Vieiras (MA). No mesmo mês, o jovem Dorivan do povo Guajajara da Terra Indígena Arariboia foi encontrado morto e esquartejado na cidade de Amarante, Maranhão. Em novembro, o líder indígena Paulo Paulino Guajajara foi assassinado dentro da mesma terra". Disponível em: https://www.cartacapital.com.br/sociedade/quinta-lideranca-indigenaguajajara-e-assassinada-no-maranhao/. Acesso em: 01 jul. 2021.
} 


\section{ATOS DE \\ PESQUISA \\ EM EDUCAÇÃO}

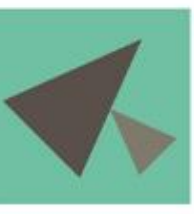

ISSN: 1809-0354

13

Em outras obras também encontramos vários objetos do cotidiano, conforme Figura 7. Ele utiliza da repetição para evidenciar o objeto, o consumismo exacerbado em nossa sociedade, a massificação dos objetos para serem consumidos por todos.

Figura 7- Paulo César Alves de Carvalho. Liquidificador, 2000. Pintura sobre azulejo.

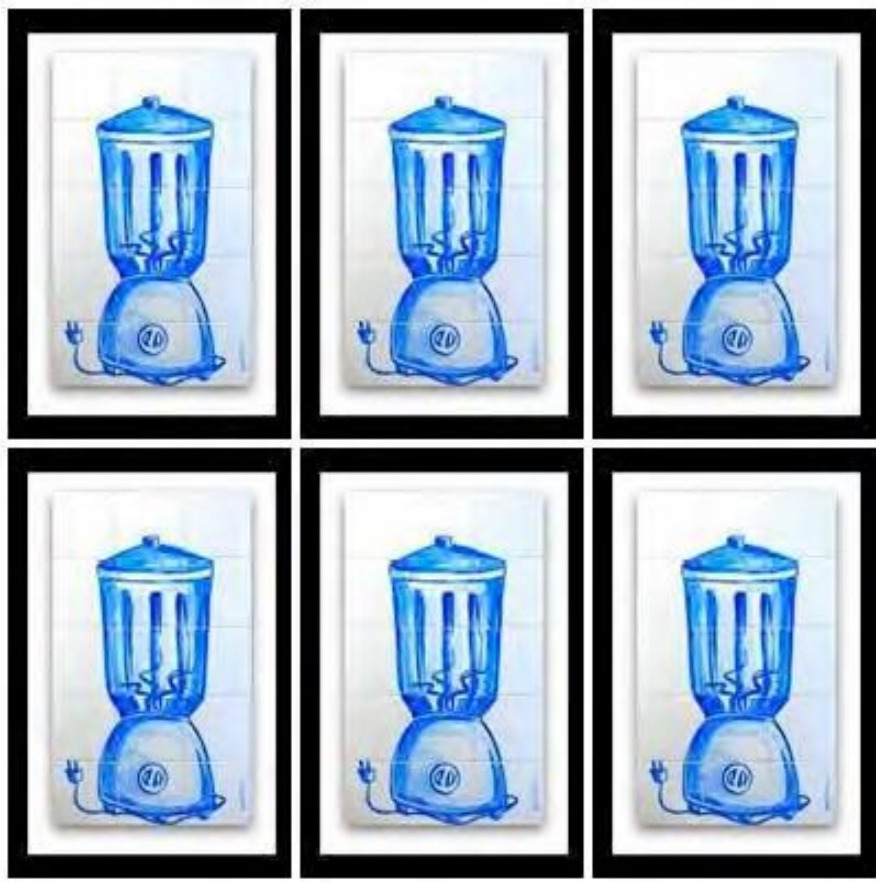

Fonte: PERINI, 2017, p. 234.

Observamos nessa obra de Paulo Cezar Alves de Carvalho o mesmo recurso artístico que Andy Warhol ${ }^{5}$ utilizou em muitas de suas obras na década de 60, a repetição com ritmo uniforme. Esse processo mostra a produção em série das indústrias, a generalização, a uniformização, a perda da identidade, a massificação, enfatizando a ideia de quantidade em detrimento da qualidade, aspectos inerentes à sociedade capitalista.

As obras de Paulo Cezar Alves de Carvalho mostram o que é peculiar na cidade e na sociedade como um todo. Ele apresenta os objetos incorporados no cotidiano como denúncia de fatos sociais. $\mathrm{O}$ artista utiliza o azulejo como suporte e a cor mais representativa em seus trabalhos é o azul cobalto, influência direta dos azulejos

\footnotetext{
${ }^{5}$ Andy Warhol (1928-1987) foi um pintor e cineasta norte-americano, um importante artista da Pop Art, lembrado por suas pinturas nas latas de sopa Campbell e principalmente pela sequência de retratos de Marilyn Monroe. Disponível em: https://www.ebiografia.com/andy_warhol/. Acesso em: 08 mai. de 2021.
} 


\section{ATOS DE \\ PESQUISA \\ EM EDUCAÇÃO}

ISSN: 1809-0354

14

portugueses do centro histórico de São Luís, estudados por ele, em Lisboa, no Museu Nacional do Azulejo.

Outro artista de São Luís é Márcio Vasconcelos, fotógrafo, que tem se dedicado a registrar a cultura popular e religiosa dos afrodescendentes no Maranhão. Entre tantos prêmios e exposições escolhemos alguns trabalhos para situá-lo nesse estudo. $\mathrm{Na}$ Figura 8, encontramos uma fotografia do projeto Nagon Abioton - Um Estudo Fotográfico e Histórico sobre a Casa de Nagô, aprovado na Lei Rouanet e no Programa Petrobras Cultural/2009. Esse ensaio-documentário-fotográfico transformou-se em livro sobre um dos terreiros mais antigos do Tambor de Mina no Maranhão.

Figura 8- Márcio Vasconcelos, Fotografia.

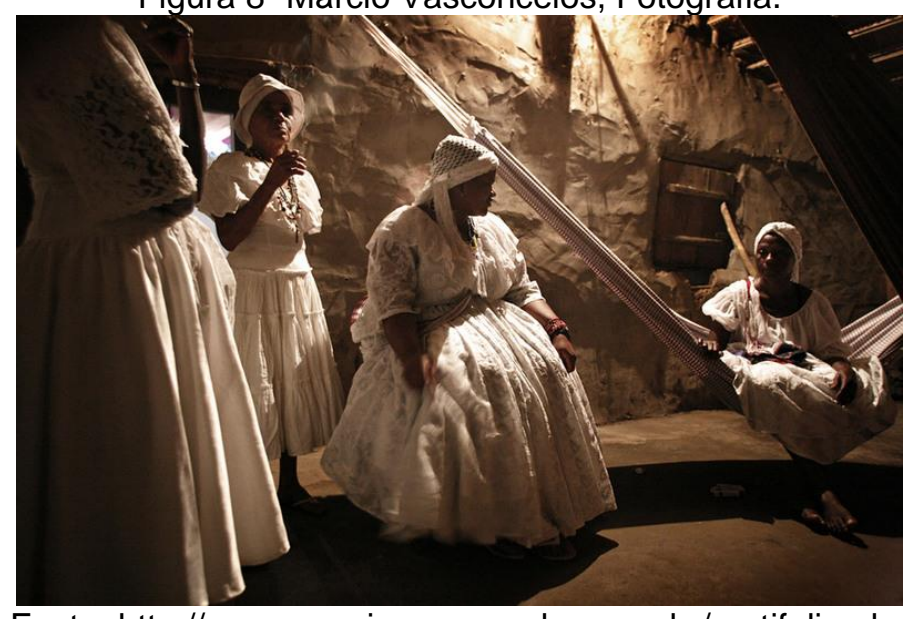

Fonte: http://www.marciovasconcelos.com.br/portifolio.php

No Maranhão desenvolveram-se muitas religiões afro-brasileiras, como o Candomblé, a Umbanda e o Tambor de Mina que tem duas origens: Jeje e Nagô. "Existem duas casas matrizes fundadas por africanos: a Casa das Minas Jeje, de origem daomeana, que não possui filiais e a Casa de Nagô, de origem iorubana de onde derivaram a maioria dos terreiros de Mina" (FERRETTI, 2011, p. 247). O autor afirma que em São Luís são numerosos os terreiros de Tambor de Mina e a comunidade que participa é normalmente da classe trabalhadora. $O$ autor acrescenta informando que esses grupos de cultos religiosos organizam festas populares que são consideradas como foco de desenvolvimento cultural, com atividades de danças, cânticos, músicas, artesanato, medicina popular, culinária entre outros elementos. Essas festas acontecem o ano todo. Ele considera essas festas nos terreiros como "[...] fenômenos sociais totais, que envolvem elementos políticos, jurídicos, 


\section{ATOS DE

ISSN: 1809-0354

econômicos, estéticos, religiosos, morais, etc., em torno de regras de reciprocidade e de obrigatoriedade" (FERRETTI, 2011, p. 244). Percebemos, então, que os terreiros são integrados à sociedade local, possuindo laços de fraternidade e de conquistas. A importância dessa manifestação expressa-se nos campos religiosos, culturais, históricos, artísticos, políticos e sociais. Muitos são os motivos pelos quais Márcio Vasconcelos traz o terreiro Tambor de Mina para sua obra, podendo ser contemplado pelo resto do mundo.

Márcio Vasconcelos também foi vencedor do $1^{\circ}$ Prêmio Nacional de Expressões Culturais Afro-brasileiras/2010 pela Fundação Cultural Palmares/Petrobras com o projeto Zeladores de Voduns do Benin ao Maranhão. Nesse projeto, ele retratou por mais de um ano os cultos e todas as pessoas que mantêm a tradição no Maranhão, além de passar 25 dias em Benin, na África para estabelecer um paralelo entre os zeladores dos dois lugares. Esse trabalho culminou numa exposição que já foi possível ser contemplada em três cidades brasileiras: Maranhão, no Museu Casa de Nhozinho e no Museu de Artes Visuais; em Salvador, no Museu Casa do Benin; e em São Paulo, no Museu AfroBrasil. Essas obras da exposição fotográfica mostram as semelhanças entre Sacerdotes de culto a voduns na África e no Brasil, que podemos contemplar na Figura 9.

Figura 9- Márcio Vasconcelos. Sacerdotes de culto a Voduns, Fotografia.

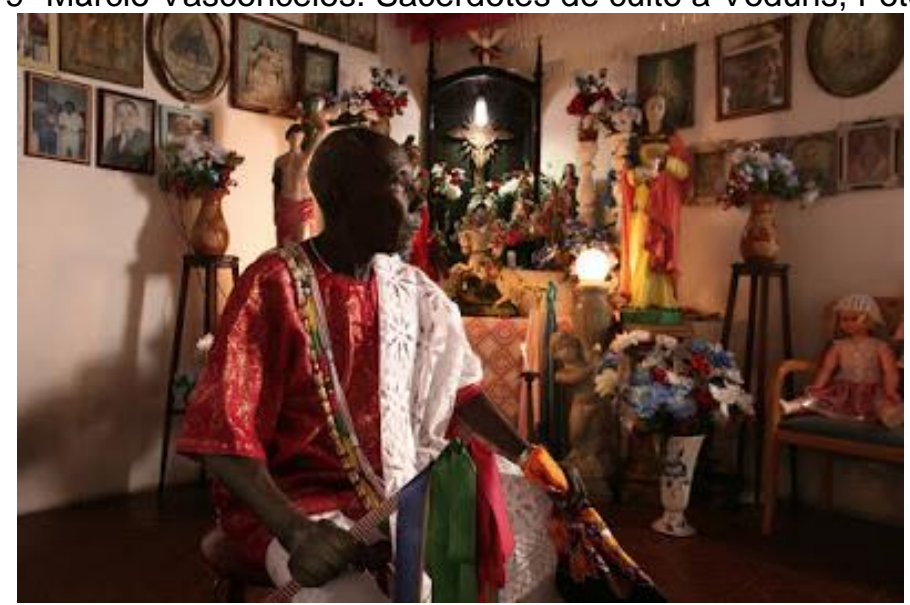

Fonte: http://www.marciovasconcelos.com.br/portifolio.php

Voduns é o termo utilizado para representar os pais e mães de santo do Tambor de Mina. O professor de sociologia da USP explica:

Em São Luís e outras cidades do Maranhão, a religião dos voduns recebeu o nome de tambor-de-mina: alusão à presença constante dos tambores nos 


\section{ATOS DE \\ PESQUISA \\ EM EDUCAÇÃO}

ISSN: 1809-0354

16

rituais e aos escravos minas, como eram ali designados os negros sudaneses. Trata-se de religião iniciática e sacrificial, em que os sacerdotes são ritualmente preparados para "receber" as divindades em transe. As entidades manifestadas, que podem ser voduns ou encantados (espíritos), vêm à terra para dançar em cerimônias públicas denominadas tambor. As entidades são assentadas (fixadas em artefatos sacros) e recebem sacrifício, com oferta de animais, comidas, bebidas e outros presentes. Segundo tradição africana que se manteve no Brasil, cada humano pertence a um vodum, sendo para ele ritualmente consagrado em cerimônias iniciáticas, como ocorre no candomblé dos orixás (PRANDI, 1997, p. 111).

O culto dos voduns foi trazido para o Brasil por escravos procedentes do antigo Reino do Daomé, hoje República do Benin. O Maranhão é conhecido, por alguns, como terra dos voduns, temática bastante explorada por muitos artistas.

Vasconcelos percorre o Nordeste, em especial o Maranhão, retratando com seu olhar a cultura de seu povo. Ao ser questionado em uma entrevista se a fotografia era uma ferramenta para traduzir a realidade, ele responde:

A imagem fotográfica, independente de como for capturada, sempre será um
importante instrumento para mostrar uma realidade, fazer uma denúncia, de
estar presente. [...] Sabemos que por mais que o fotógrafo tente manter certa
"distância" da sua obra, ela acaba sofrendo influência por parte dos filtros
sociais, culturais e pessoais do próprio fotógrafo (GUEDES, 2012, p. 01).

O artista cria sua obra levando em consideração o meio social e cultural em que vive. $\mathrm{O}$ artista representa aquilo que conhece. Coloca em sua obra toda sua bagagem, suas experiências sociais e conhecimentos. Na entrevista ele destaca: "Quero fazer a minha versão daquilo que vi e senti" (GUEDES, 2012, p. 01). Em seu ensaio fotográfico com base na obra de Ferreira Gullar, "Poema sujo", ele traz sua vivência do Maranhão e demonstra com sensibilidade o que o escritor maranhense Ferreira Gullar escreve na década de 70 sobre São Luís, enquanto estava exilado em Buenos Aires durante a ditadura militar.

As fotografias de Vasconcelos, inspiradas na obra literária foram transformadas em um livro "Visões de um poema sujo", editado pela Editora Vento Leste. Pode-se observar na Figura 10 um fragmento desse livro. 


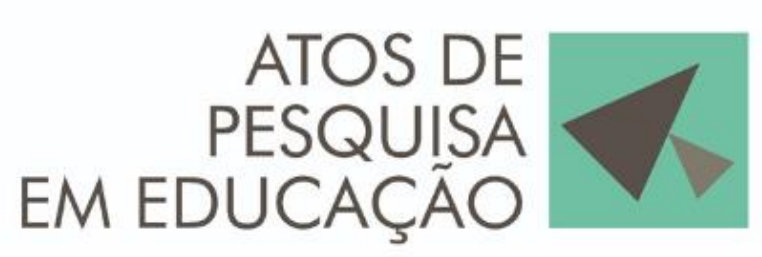

ISSN: 1809-0354

17

Figura 10- Márcio Vasconcelos. Visões de um poema sujo, Fotografia.

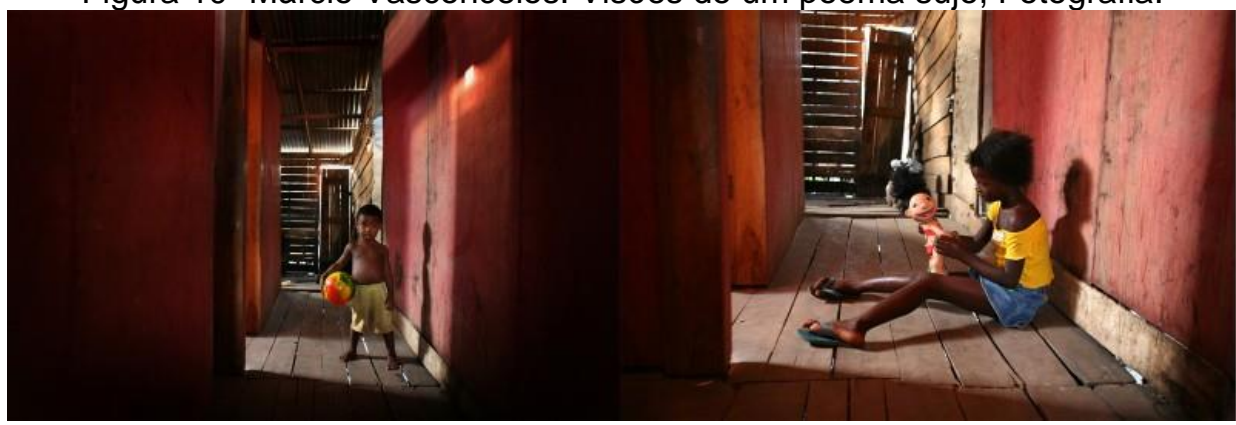

Fonte: http://www.marciovasconcelos.com.br/portifolio.php

O artista nesta obra exibe a inocência da infância, apresentando crianças com brinquedos. A bola e a boneca são os brinquedos mais comuns da nossa sociedade. Crianças de todas as classes e de todas as faixas etárias brincam com esses brinquedos, que se diferenciam apenas pelo tamanho e material. Os retratos, como o da Figura 10, originam-se da classe trabalhadora. São brinquedos simples, de baixo custo econômico, produzidos industrialmente. Mas não deixam de simbolizar o brincar, objetos que facilitam a imaginação, a criação e a fantasia, ações importantíssimas para a formação cultural e social do ser humano. O brinquedo traz a ideia de que o mundo pode ser reinventado. Esses elementos se contrapõem com o ambiente claustrofóbico criado pelo artista em sua obra. A porta fechada, o espaço escuro nos transporta para um mundo de violência e criminalidade.

O Maranhão tem um índice alto de violência contra crianças e adolescentes. Conforme os dados do serviço Disque Ministério dos Direitos Humanos ${ }^{6}$, o Maranhão houve 2604 denúncias no ano de 2017. Um número elevado, mas não real, pois ainda há os que não foram denunciados. Observando o poema de Ferreira Gullar, podemos refletir sobre esses dados:

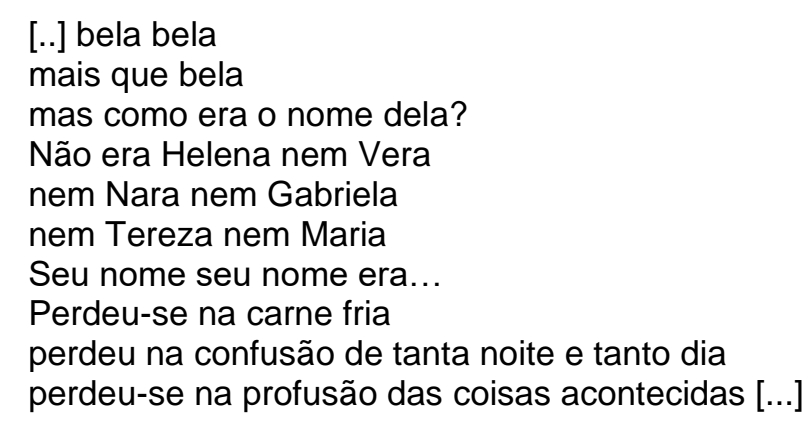

${ }_{6}^{6}$ Disponível em: http://www.mdh.gov.br/informacao-ao-cidadao/ouvidoria/dados-disque-100. Acesso em: 13 jul. 2021. 


\section{ATOS DE \\ PESQUISA \\ EM EDUCAÇÃO}

ISSN: 1809-0354

(Poema Sujo, Ferreira Gullar) ${ }^{7}$.

De tantas coisas acontecidas, de tantos abusos, dominação, exploração e opressão contra crianças e adolescentes, eles perdem seu nome, perdem sua singularidade, se tornando mais um número na estatística.

Em outra obra de Márcio Vasconcelos do livro "Visões de um poema sujo", podemos contemplar o centro histórico de São Luís, Figura 11.

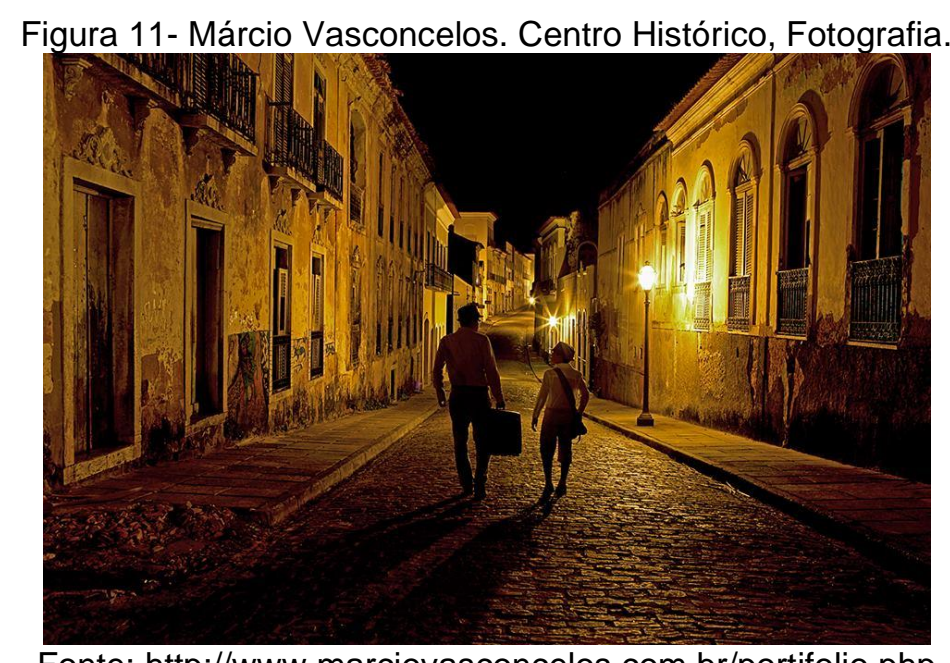

O elemento mais valorizado nesta fotografia é a luz. Na iluminação percebe-se o efêmero, o instante capturado pela lente do artista. Ferreira Gullar também evidencia a importância da luz:
[...] saímos de casa às quatro com as luzes da rua acesa meu pai levava a maleta eu levava uma sacola rumamos por Afogados outras ladeiras e ruas o que para ele era rotina para mim era aventura [...] (Poema sujo, Ferreira Gullar).

O fotógrafo consegue captar a poética de Ferreira Gullar. Sua obra, Figura 11, traduz o silêncio, a cumplicidade do homem e do menino, do pai e do filho, como escreve o poeta, da classe trabalhadora que levanta cedo para trabalhar.

\footnotetext{
${ }^{7}$ Disponível em: http://static.recantodasletras.com.br/arquivos/5319037.pdf. Acesso em: 28 jun. 2021.
} 


\section{ATOS DE \\ PESQUISA \\ EM EDUCAÇÃO}

ISSN: 1809-0354

19

O centro histórico de São Luís é um lugar especial para Márcio Vasconcelos. Ele o retrata de uma forma singular, como se pode contemplar na Figura 12 e 13.

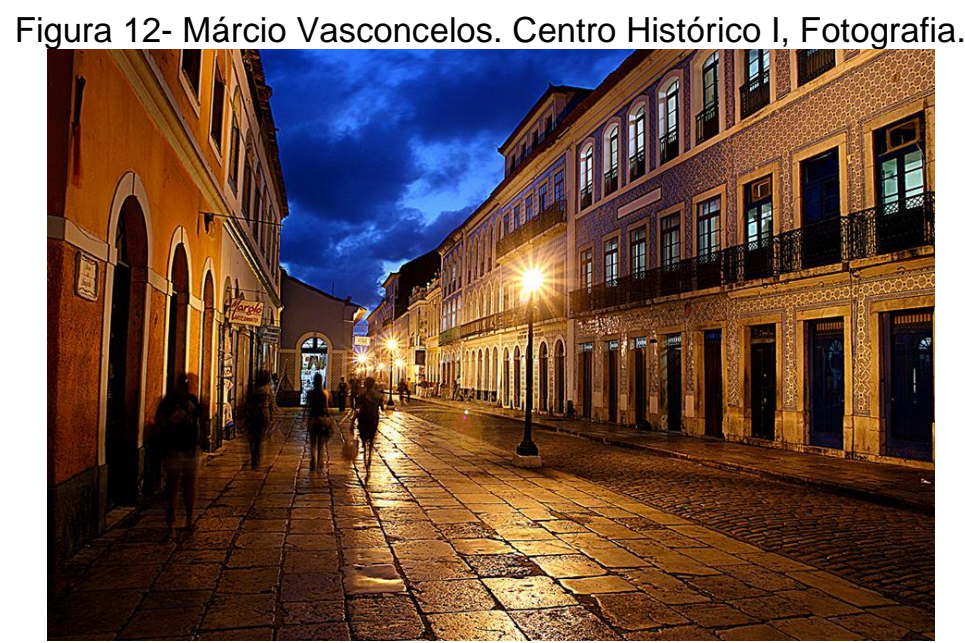

Fonte: Acervo do artista.

Na obra de Márcio Vasconcelos encontramos uma linha tênue entre a relação estética da realidade e da representação. Para Kossoy (2008), a fotografia é uma representação a partir do real segundo o olhar e a ideologia do fotógrafo, é a construção de realidades. Para o autor, a fotografia "[...] busca incessante em captar e interpretar a vida e não a de tentar, exclusivamente, reproduzi-la" (KOSSOY, 2008, p. 02). O autor afirma que é sempre construída a imagem fotográfica por mais documental que seja o conteúdo.

Vázquez (2010) também escreve sobre a arte de refletir a realidade. Para o autor, o artista ao refletir a realidade, reflete-se a si mesmo, e consequentemente, sua época e sua classe. Com a entrada da imagem fotográfica, Galard (2012), nos lembra que começa o questionamento da realidade ou ficcionalidade da obra. A fotografia capta a realidade, apreendendo o momento. A representação é ficcional, mas é baseada na realidade. Para 0 autor, a dicotomia criada entre realidade $\mathrm{e}$ representação, cria uma complicação interpretativa, capaz de nos desorganizar, unificando arte e vida. Para ele, no mundo contemporâneo, a realidade bruta está cada vez mais sendo introduzida na criação artística.

Márcio Vasconcelos apresenta o centro histórico e, nele, a imagem representada é a junção da realidade da cidade e da imaginação do artista. É a união entre arte e vida. A fotografia dele é única. Muitas outras podem existir a partir da mesma rua, do mesmo espaço urbano, tirada pelo mesmo ângulo, porém nunca vai 


\section{ATOS DE \\ PESQUISA \\ EM EDUCAÇÃO}

ISSN: 1809-0354

20

ser igual, pois as experiências, os olhares, a cultura de cada fotógrafo fazem parte de cada obra. O Tambor de Crioula, também não passou despercebido a este artista, como podemos observar na Figura 13.

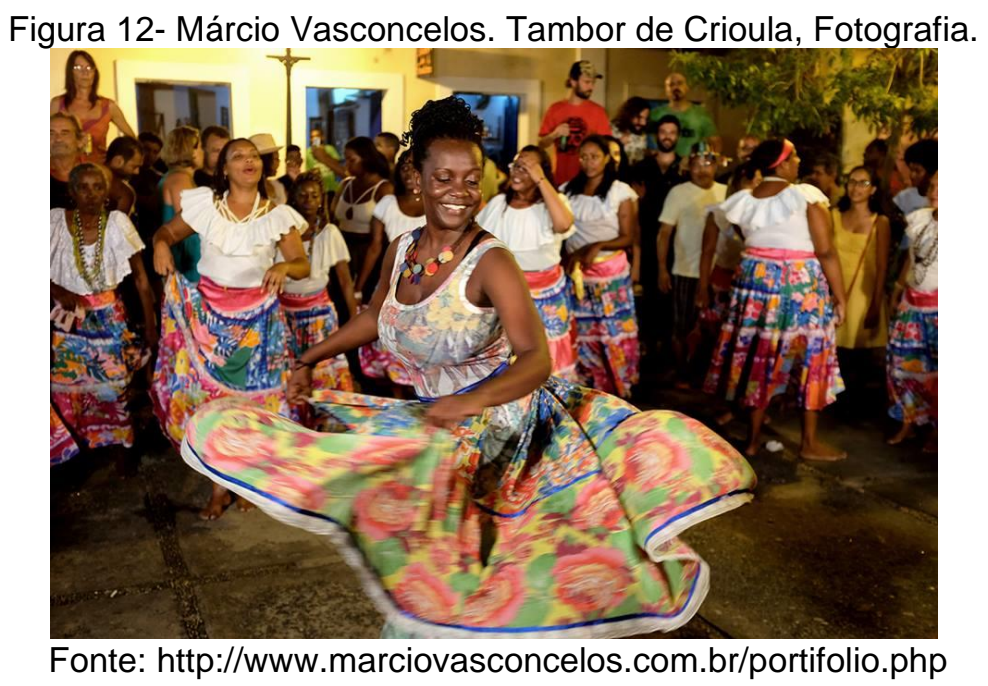

Ele representou a cultura popular afro-brasileira com suas cores e encantos. A alegria é contagiante quando se olha para a obra. O elemento mais valorizado nesta fotografia é o movimento. $O$ artista conseguiu capturar o movimento da saia, o giro, a exaltação da magia da dança. As fotografias dele apresentam e representam fragmentos de uma realidade tão vasta e rica, que é a do Nordeste. Porém, a importância de sua obra não é apenas documental. Além de registrar a cultura popular e religiosa do Nordeste, em especial a do Maranhão, sua obra suscita prazer ao ser contemplada.

\section{CONSIDERAÇÕES}

As obras de Paulo César e de Márcio Vasconcelos nos mostram a cidade de São Luís, imaginada, representada e capturada por suas lentes e experiências culturais e sociais. Em São Luís, encontramos o convívio do novo com o antigo. No centro histórico, nos deparamos com a presença do passado glorioso e dominador, nos elementos da arquitetura colonial luso-brasileiro e nos azulejos portugueses e, ao mesmo tempo, com elementos do tempo atual, cheios de vida nos espaços revitalizados e cheios de medo nos lugares abandonados. É a junção do passado e do presente, da cultura urbana com a cultura popular, do produto histórico com o 


\section{ATOS DE \\ PESQUISA \\ EM EDUCAÇÃO}

ISSN: 1809-0354

artístico, do público com o privado, do negro com o branco, da burguesia com o proletariado, do local com o global, do caos com a ordem. O visitante se perde no labirinto do centro histórico para conhecer cada beco, cada rua, casarão, apreciando a identidade cultural da cidade.

A cidade de São Luís e as obras dos dois artistas foram aqui apresentadas por um viés interpretativo particular. Como seres socializados, aprendemos a interpretar o mundo que nos rodeia, seja ele cultural ou natural, fazendo relações históricas e sociais. E é nisso que encontramos a grandeza de se estudar a imagem estética a partir do método dialético.

Consideramos que a cidade desempenhou um importante papel na produção econômica do Brasil por ser uma cidade portuária. É reconhecida internacionalmente pelas belas fachadas dos sobrados, revestidos de azulejos portugueses, no centro histórico da cidade, além da diversidade cultural existente, principalmente pela miscigenação do índio, do negro e do europeu.

\section{JANINE ALESSANDRA PERINI}

Professora de Artes Visuais da Universidade Federal do Maranhão, Campus São Bernardo. Doutora em Artes Visuais pelo PPGAV/ UDESC, mestra em "Artes Visuais", pela mesma universidade (2012), especialização em "O Ensino da Arte: Fundamentos Estéticos e Metodológicos" (1998) e em "Arteterapia" (2007), graduação em Educação Artística (1998) e em Pedagogia (2020).

\section{REFERÊNCIAS}

ARGAN, G. C. História da arte como história da cidade. Tradução Pier Luigi Cabra. 5ํㅡ. Ed.- São Paulo: Martins Fontes, 2005.

ASSIS, I. B. A herança lusitana da cidade dos azulejos. 2012. Disponível em: http://www.egov.ufsc.br/portal/conteudo/heran\%C3\%A7-lusitana-da-cidade-dosazulejos. Acesso em: 28 jun. 2021.

BENJAMIN, W. Passagens. Belo Horizonte: UFMG, 2006.

FERRETTI, S. F. Comida ritual em festas de Tambor de Mina no Maranhão. Horizonte: revista de Estudos de Teologia e Ciências da religião. Belo Horizonte, v. 9, n. 21, p. 242-267, abr./jun. 2011. Disponível em: file:///C:/Users/luca/Downloads/DialnetComidaRitualEmFestasDeTamborDeMinaNoMaranhao-3741063.pdf. Acesso em: 13 jul. de 2021. 


\section{ATOS DE \\ PESQUISA \\ EM EDUCAÇÃO}

ISSN: 1809-0354

FIGUEIREDO, T. N. S. C. Expressões e desafios do restauro arquitetônico em edificações da arquitetura luso-brasileira no Centro Antigo da cidade de São Luís (MA/Brasil). Dissertação (Mestrado em Arquitetura). Faculdade de Arquitetura e Urbanismo da Universidade de São Paulo. São Paulo, 2012.

GALADR, J. Beleza exorbitante: Reflexões sobre o abuso estético. São Paulo, FapUnifesp, 2012.

GUEDES, D. A fotografia documental de Márcio Vasconcelos. 2012. Disponível em: http://www.saraivaconteudo.com.br/Materias/Post/45648. Acesso em: 23 jun. 2021.

KOSSOY, B. O paradigma da fotografia. Seminário de Fotografia. Chile, 2008.

Disponível em: http://boriskossoy.com/wp-

content/uploads/2014/11/paradigma_pt.pdf. Acesso em: 14 jun. de 2021.

PEREIRA, J. J. As representações da escravatura na imprensa jornalística do Maranhão na década de 1880. 2006. Tese (Doutorado em História Social).

Universidade de São Paulo, São Paulo, SP. Disponível em:

https://teses.usp.br/teses/disponiveis/8/8138/tde-11072007-

103448/publico/TESE_JOSENILDO_JESUS_PEREIRA.pdf. Acesso em: 11 abr. de 2021.

PERINI, J. A. Entrevista com Paulo Cezar Alves de Carvalho. In: Revista Educação, Artes e Inclusão. Volume 13, № 1. Jan./Abr., 2017. Disponível em: http://www.revistas.udesc.br/index.php/arteinclusao/article/view/9543. Acesso em: 21 jun. 2021.

PINHEIRO, P. E. A cidade como obra de arte: do renascimento à cidade burguesa. In: CARDOSO, S. P.; PINHEIRO, P. E.; CORRÊA, E. L. (orgs.). Arte e Cidades: imagens, discursos e representações. EDUFBA, 2008.

VÁZQUEZ, A. S. Um convite à estética. Trad.: Gilson Baptista Soares. Rio de Janeiro: Civilização Brasileira, 1999.

VÁZQUEZ, A. S. As ideias estéticas de Marx. Trad. Carlos Nelson Coutinho. 3. ed. São Paulo: Expressão Popular, 2010.

Recebido em: 23/07/2021.

Aprovado em: 20/08/2021. 